\title{
ZONA DE AMORTECIMENTO DO PARQUE ESTADUAL NOVA BADEN NO MUNICÍPIO DE LAMBARI: aspectos jurídicos e ambientais
}

\author{
Solange Lemgruber BOECHAT ${ }^{1}$ \\ Wagner Saraiva Ferreira Lemgruber BOECHAT ${ }^{2}$ \\ Mariane Silva PARÓDIA ${ }^{3}$ \\ Malu Mendes PEREIRA ${ }^{4}$
}

\begin{abstract}
${ }^{1}$ Coordenadora da Agência Avançada de Meio Ambiente em São Lourenço - MG. Bacharel em Biologia, pós-graduada em Ecoturismo, em Interpretação e Educação Ambiental e em Administração e Manejo de Unidades de Conservação. Pesquisadora do Grupo de Estudo e Pesquisa Aplicados em Direito. estudosdedireitoaplicado@ gmail.com

${ }^{2}$ Advogado, consultor ambiental, professor universitário, pós-graduado em Direito Público, em Direito Ambiental e Urbanístico e em Direito Tributário. Pós-graduando em Docência do Ensino Superior. Mestre em Direito pela Faculdade de Direito do Sul de Minas Gerais. Coordenador do Grupo de Estudo e Pesquisa Aplicados em Direito. estudosdedireitoaplicado@gmail.com

${ }^{3}$ Advogada, professora universitária e especialista em Direito Civil pela Universidade Anhanguera. Pós-graduanda em Docência do Ensino Superior. Coordenadora do Grupo de Estudo e Pesquisa Aplicados em Direito. estudosdedireitoaplicado@gmail.com

${ }^{4}$ Auditora Fiscal da Receita Estadual (MG), professora universitária, pós-graduada e mestre pela Faculdade de Direito do Sul de Minas (FDSM). Coordenadora do Grupo de Estudo e Pesquisa Aplicados em Direito.

estudosdedireitoaplicado@gmail.com
\end{abstract}

Recebido em: 17/05/2016 - Aprovado em: 10/03/2017 - Disponibilizado em: 01/07/2017

\section{RESUMO:}

O presente artigo, por meio de uma abordagem interdisciplinar do Direito e da Biologia, tem o intuito de analisar o atual estado da zona de amortecimento do Parque Estadual Nova Baden. Para tal foi feita uma pesquisa de campo com a aplicação de questionário aos proprietários de terras dessa área e posteriormente feita uma análise dos dados aliada a uma revisão bibliográfica dos temas relevantes para o estudo. $\mathrm{O}$ estudo pôde constatar que o meio ambiente da zona de amortecimento ainda se encontra em bom estado de conservação; verificou-se ainda a fragilidade das normas estatuídas pelo plano de manejo, principalmente no que diz respeito à sua aplicação e que o Parque se encontra totalmente isolado da comunidade circunvizinha.

Palavras-Chave: Zona de Amortecimento, Parque Estadual Nova Baden, Direito, Meio Ambiente, Proprietários.

\section{NOVA BADEN STATEPARK'S BUFFER ZONE IN LAMBARI COUNTY: legal and environmental aspects}

\begin{abstract}
:
This article, through an interdisciplinary approach between Law and Biology, aims to analyse the current situation of the New Baden State Park's buffer zone. It was made a field survey with a questionnaire to land owners of the area and then made an analysis of data combined with a literature review of the relevant subjects for the study. The study points to the environment of the buffer zone is still in good condition; it was also founda fragility of management plan's norms, especially with regard to its application. The park is completely isolated from the surrounding community.
\end{abstract}

Keywords: Buffer Zone, Nova Baden State Park, Law, Environment, Land Owners. 


\section{Introdução}

O presente artigo, através de uma abordagem interdisciplinar do Direito e da Biologia, tem o intuito de analisar o atual estado da zona de amortecimento do Parque Estadual Nova Baden localizado no Município de Lambari.

Tal análise se destina a verificar a conformidade e efetividade jurídica do plano de manejo, confirmar se os ditames do referido plano estão sendo de fato cumpridos, constatar se há a interação da unidade com a comunidade diretamente afetada pela zona de amortecimento e levantar o estado socioambiental da área.

Para isso a pesquisa se valeu de método misto que incluiu revisões bibliográficas e pesquisa de campo com os proprietários de terras no interior da zona de amortecimento, os quais responderam ao questionário previamente elaborado.

O estudo se justifica duplamente, pois do ponto de vista científico, além de ser o primeiro trabalho científico na zona de amortecimento do Parque Estadual Nova Baden, tem relevância jusambiental, pois demonstra como a execução dos ditames do Sistema Nacional de Unidades de Conservação, do Código Florestal e os ordenamentos de gestão democrática têm se descortinado na prática; já do ponto socioambiental apresenta visão única da interação homem x natureza e, do ponto de vista biológico, complementa e revê vários pontos do plano de manejo e, concomitantemente, integraliza o vazio científico deixado pelo Estado na área. De um ponto de vista prático o estudo aponta várias falhas e campos de ação tanto para o Estado como para a comunidade, podendo ser usado como marco de partida para políticas públicas e planos sociais.

\section{Metodologia}

A pesquisa comportou três fases distintas: levantamento preliminar, pesquisa de campo e análise de resultados através de levantamento bibliográfico secundário.

$\mathrm{Na}$ fase de levantamento preliminar, foram verificados os principais pontos a serem estudados, tanto do ponto de vista biológico como do jurídico. Isso se deu com base no plano de manejo e direitos correlacionados com o tema. Sendo, portanto, esse momento caracterizado por uma pesquisa bibliográfica e uma análise hipotética dedutiva.

Com base nesses dados, elaborou-se assim questionário contendo 37 perguntas. Importante ressaltar que para evitarem-se as variações de nomes regionais das espécies da fauna e flora, optou-se por mostrar ao entrevistado foto dessas. A origem dessas fotos se encontra indicada, no decorrer deste 
trabalho, como citação logo após o nome espécime.

A segunda fase comportou a aplicação do questionário ao grupo de amostragem. Sendo que para que se chegasse ao grupo de amostragem foram levados em conta dois fatores: o espacial e $\mathrm{o}$ de amostragem propriamente dito.

A zona de amortecimento (ZA) do Parque Estadual Nova Baden (PENB) comporta três municípios, porém a pesquisa se foca no Município de Lambari - MG; portanto a limitação espacial gera a zona de estudo - a área entendida pelo plano de manejo da unidade de conservação (UC) no Município de Lambari.

A escolha por essa faixa territorial se deve ao fato de suas interações humanas, e até certo ponto biológicas, divergirem do restante da ZA, pois a Serra das Águas age como barreira isolando a região estudada do restante da ZA. Esse isolamento é reforçado pela dificuldade de acesso ao restante da ZA (que somente pode ser feito, a partir do PENB, por uma estrada de terra ou se tomando vias alternativas paralelas à ZA, de modo que é muito mais custosa a chegada a qualquer ponto da ZA nos demais municípios do que a chegada a qualquer ponto da ZA em Lambari); situação essa agravada pelo fácil acesso e movimentação na área de Lambari devido a toda ZA ser margeada por rodovia asfaltada; o que leva aos habitantes dessa região terem pouco ou quase nenhum contato com o restante da ZA. Soma-se a isso a maior ligação histórica, social e econômica do PENB com o Município de Lambari, conforme se demonstrará no decorrer deste trabalho. Além disso, o grau de conservação dos ecossistemas na ZA em Lambari é sensivelmente maior do que no restante da ZA. Assim, considerando o fator humano e o biológico pode-se afirmar que existem duas porções na ZA, uma que abrange o município de Lambari e outra que encampa os demais municípios. Justificando-se a limitação municipal escolhida.

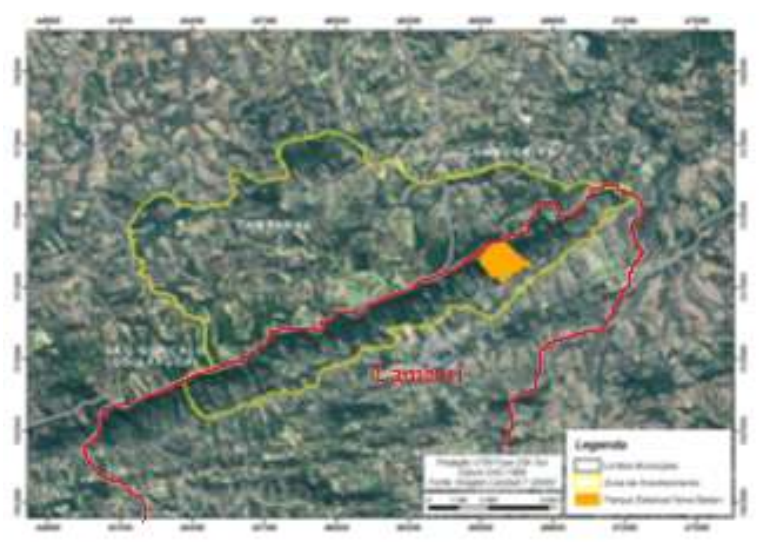

Figura 1: Área da Zona de Amortecimento (em amarelo) do Parque Estadual Nova Baden (em laranja) no Município de Lambari (em vermelho).

Fonte: Mapa modificado do original disponível em IEF, Encarte 1, 2010, p.6.

Para amostragem foi traçada linha paralela à Serra das Águas, a qual se iniciava em um dos extremos da ZA e se findava na outra. 
Foram então elencados pontos de coleta de dados, distantes um do outro por cerca de 1 a 3 quilômetros; o que resultou em 18 pontos de coleta. Ao redor desses pontos, o questionário foi aplicado a pelo menos um proprietário e a no máximo dois proprietários, sempre de grupos familiares diversos. Isso resultou em um grupo de amostragem de 32 entrevistados.

A terceira fase comportou levantamento bibliográfico secundário voltado a análise dos dados; adotando-se novamente o método hipotético dedutivo.

\section{Os parques no Direito Ambiental}

O Direito Ambiental é um conjunto de normas de vários ramos da Ciência Jurídica que se congregam ao redor de um mesmo ponto focal: o meio ambiente [ANTUNES, 2014. NETTO, 2009]. Portanto sua interação com as ciências naturais tais com a biologia é incontestável.

Entretanto, compatibilizar as atividades humanas com a conservação do meio ambiente natural não é das tarefas mais fáceis. [MILANO, 2002]

Nesse contexto, a mata atlântica, biota na qual se insere o Município de Lambari, Minas Gerais, sofreu ao longo dos séculos massiva diminuição em sua área e forte fragmentação dos espaços restantes e que geralmente se localizam em áreas de difícil acesso. [ BORÉM e RAMOS, 2002.]

Desses embates surgiram, e ainda surgem, várias normas com o objetivo de proteger o meio ambiente e, ao mesmo tempo, possibilitar o avanço da humanidade. Uma dessa normas é o Sistema Nacional de Unidades de Conservação (SNUC), que normatiza a possibilidade de criação de espaços especialmente protegidos - unidades de conservação (UC) definidas pelo Sistema Nacional de Unidades de Conservação como: "[...] espaço territorial e seus recursos ambientais, [...], com características ambientais relevantes, legalmente instituído pelo Poder Público com objetivos de conservação e limites definidos, sob regime especial de administração, ao qual se aplicam as garantias adequadas de proteção" [BRAZIL, 2000].

Devido a sua importância, as três esferas da federação têm competência para criação de UCs. [THOMÉ, 2015]

Ocorre que para consecução dos objetivos pretendidos pelo legislador, tornou-se necessária a criação de diversos tipos de UC; sendo certo que esses podem ser genericamente classificados em dois grupos: unidades de proteção integral e unidades de uso sustentável. [ANTUNES, 2014. THOMÉ, 2015] 
Pode-se definir unidades de proteção integral como espaços nos quais os usos antrópicos somente são possíveis de forma indireta (salvo estipulação legal) e tem como principal objetivo a preservação do meio ambiente natural [ANTUNES, 2014]. Nessa classificação se inserem os parques (sejam eles nacionais ou estaduais); motivo pelo qual as UCs de proteção integral se mostram mais relevantes para este estudo, pois o Parque Estadual Nova Baden (PENB) se enquadra nessa categoria.

Os parques são UCs peculiares e tem fins múltiplos, atendem tanto à conservação do meio ambiente como ao laser, sendo assim o tipo de UC mais conhecido pela população [ANTUNES, 2014]. Importante ainda ressaltar que, quando se fala em laser, se está ainda incluindo a conservação de sítios de grande beleza cênica [THOMÉ, 2015].

Esse regime jurídico é de extrema relevância, pois compatibiliza as funções ambientais com as antrópicas de um modo marcadamente relevante para a educação ambiental, já que as atividades de turismo e educação ambientais não aparecem como auxiliares, mas sim como principais, como bem salienta Thomé [2015], que ressalva, entretanto, que a visitação, e também a pesquisa científica, ficarão condicionadas aos ditames do Plano de Manejo (PM).

\subsection{Parque Estadual Nova Baden.}

E Esta unidade de conservação está localizada no Município de Lambari, sul de Minas Gerais, a $339 \mathrm{~km}$ de Belo Horizonte [IEF, 2015a.], tendo como ponto central as coordenadas $45^{\circ} 19^{\prime} 11,17^{\prime \prime} \mathrm{O}$ e $21^{\circ} 56^{\prime} 9,22^{\prime} ' \mathrm{~S}$ [IEF, 2006.], a aproximadamente $5 \mathrm{~km}$ da sede municipal [IEF, Encarte 1, 2010].

O Parque apresenta, além dos requisitos de grande diversidade biológica e de sítios de beleza cênica, um coeficiente distinto, pois, além de preservar o meio ambiente natural, ainda resguarda o meio ambiente cultural local, pois em sua sede viveu, no século 19, importante figura para a cidade de Lambari: seu primeiro prefeito, Américo Wernek [IEF, 2006.]. O próprio nome do Parque é uma referência às origens desse pioneiro, remontando à cidade alemã de Baden-Baden [IEF, 2015a]

Dessa época data ainda a localidade comumente chamada de 'casarão'

"Atual sede administrativa do PENB, a edificação construída no final do século XIX em estilo colonial ainda preserva muitas de suas características originais”. [IEF, Encarte 1, 2010, p. 50]

A área, que conta com aproximadamente 215 há [IEF, encarte 1, 2010] foi incluída no patrimônio estatal após o seu 
abandono pelo Dr. Werneck, que, desgostoso da política municipal, partiu sem nunca mais retornar à localidade. [IEF, 2015a]

Por meio do Decreto $\mathrm{n}^{\circ} 16.580$, de 13 de setembro de 1974, o Estado de Minas Gerais criou a Reserva Biológica Nova Baden, que em "27/09/94, através do Decreto no 36.069 foi transformada no Parque Estadual Nova Baden, que ficou sob a administração do IEF [Instituto Estadual de Florestas]" [IEF, Encarte 1, 2010, p. 60].

Classificado como um parque de pequeno porte [IEF, 2006], a unidade tem, muito mais do que em outras unidades de conservação de maior área, a sanidade gênica de suas populações intimamente ligada à sanidade dos ecossistemas circunvizinhos. Assim a necessidade de sua ZA ser cientificamente estudada e corretamente protegida se torna preponderante.

O PENB estáhá mais de 10 anos aberto à visitação [IEF, 2015a], porém percebeu-se na pesquisa que seus vizinhos da ZA apresentam muito pouco interesse em visitá-lo, chegando a desconhece-lo. Isso se traduz em uma baixa visitação, na qual $47 \%$ dos entrevistados jamais haviam ido ao Parque, $35 \%$ há mais de cinco anos e somente18\% há menos de cinco anos.

Graficamente tem-se:

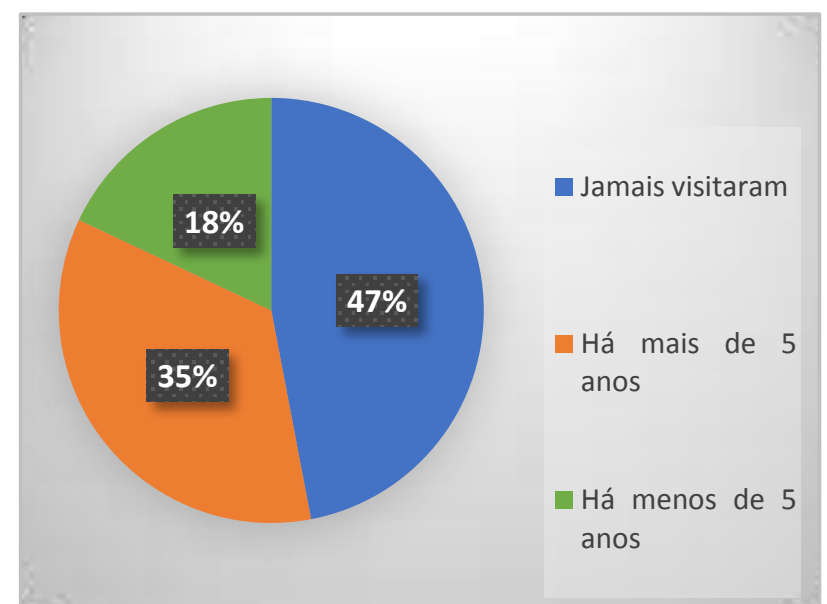

Gráfico 1: Visitação no PENB

Portanto é necessária ação imediata por parte da administração do PENB de modo a conscientizar e informar a população da ZA da existência, importânciae funções do PENB.

\section{Plano de manejo (PM)}

O PM é "instrumento técnico fundamentado nos objetivos gerais de uma unidade de conservação, estabelecendo o seu zoneamento e as normas que definirão o uso da área e o manejo dos recursos naturais, além da implantação de estruturas para gestão da unidade" [IEF, 2015b, p.13].

É ele que verdadeiramente cria a ZA, pois dele virão todas as suas características, das quais se destacam: forma, normas e gestão; fazendo-se, portanto, imperioso um breve estudo de tal instrumento.

O SNUC define ZA como "o entorno de uma unidade de conservação, onde as 
atividades humanas estão sujeitas a normas $e$ restrições específicas, com o propósito de minimizar os impactos negativos sobre a unidade" [BRAZIL, 2000].

Entretanto, em uma leitura sistemática da lei, pode-se dizer que tal documento vai além dessa definição, pois, muito mais que estabelecer somente a gestão da unidade de conservação deve "abranger não apenas a área da unidade de conservação, mas deve ainda estabelecer as normas e as restrições para a utilização da zona de amortecimento e dos corredores ecológicos" [THOMÉ, 2015, p. 76].

Assim o PM é, de fato, a lei da UC [MACHADO, 2004], uma vez que dele derivam inúmeras normas que amoldam e individualizam a unidade, de modo que cada parque, embora pertencente a um grupo específico de UC, não é juridicamente igual a outro, mas é único, pois possui normas jurídicas próprias.

Muito embora a importância desse documento seja estratégica, tanto para unidade como para seu entorno (dentro e fora da ZA), seu conhecimento ainda é extremamente baixo, pois somente $6 \%$ dos entrevistados disseram conhecer o PM do PENB, sendo que, $88 \%$ de todos os entrevistados se quer sabiam o que é um PM.

Urge ainda ressaltar que todos os entrevistados que disseram saber o que é um
PM e ou conhecer o PM do PENB, tiveram ou têm relações de parceria institucional ou trabalho com o PENB.

Desse modo o Estado deve urgentemente agir de modo a esclarecer a sociedade da importância e utilidade do PM, sob pena de verdadeiramente levar a ZA a inexistência fática.

\section{Zona de amortecimento}

No que pese a proteção dispensada às UCs, essa são muito suscetíveis às condições de suas vizinhanças; motivo pelo qual possuem ZAs, espaços que visam diminuir os impactos antrópicos na unidade de conservação. [VIO, 2001]

O SNUC traz a definição legal de ZA em seu artigo $2^{\circ}$, XVIII: “[...] entorno de uma unidade de conservação, onde as atividades humanas estão sujeitas a normas e restrições específicas, com o propósito de minimizar os impactos negativos sobre a unidade" [BRASIL, 2000].

Deve haver uma ruptura gradativa entre o meio ambiente natural, protegido nas unidades de conservação, e o ambiente externo. Essa é a principal função da zona de amortecimento, área que circunda as unidades e que, devido ao seu relevante papel, também é protegida. A zona de amortecimento não integra 
a unidade de conservação mas fica sujeita a normas e restrições específicas a serem estipuladas pelo órgão responsável pela administração da unidade. [THOMÉ, 2015, p. 422]

De acordo com o artigo 25, parágrafo $2^{\circ}$ da mesma lei, o tamanho e a forma da zona de amortecimento serão estabelecidos pelo plano PM da UC.

\subsection{Zona de amortecimento do Parque Estatual Nova Baden}

Segundo informações do PM do PENB:

Os limites da Zona de
Amortecimento (ZA) foram
definidos em Oficinas de
Planejamento realizadas em Viçosa-
MG e Lambari-MG, seguindo os
princípios do Roteiro Metodológico
para elaboração de Planos de
Manejo (IBAMA, 2002). Nesse
sentido, partiu-se do limite de 10
km ao redor da UC e aplicaram-se
critérios de inclusão e exclusão de
áreas. O principal critério de
inclusão foi a presença de
remanescentes florestais no entorno,
com ênfase na Serra das Águas; e
para exclusão, a presença de áreas
urbanas consolidadas e aquelas
previstas para expansão no Plano
Diretor do município de Lambari.
Para os ajustes do limite final foi
considerada a presença de marcos
no campo como estradas, rios,
microbacias hidrográficas e
acidentes geográficos. [IEF, Encarte
1, 2010, p.5]
Amortecimento (ZA) foram definidos em Oficinas de Planejamento realizadas em ViçosaMG e Lambari-MG, seguindo os princípios do Roteiro Metodológico para elaboração de Planos de sentido, partiu-se do limite de 10 $\mathrm{km}$ ao redor da UC e aplicaram-se critérios de inclusão e exclusão de áreas. $\mathrm{O}$ principal critério de inclusão foi a presença de com ênfase na Serra das Águas; para exclusão, a presença de áreas urbanas consolidadas e aquelas previstas para expansão no Plano Diretor do município de Lambari. Para os ajustes do limite final foi no campo como estradas, rios, microbacias hidrográficas e 1, 2010, p.5]

Analisando ambos os encartes do PM do PENB, percebe-se uma discrepância quanto à

área total da ZA, pois o encarte 1 estabelece a área da ZA em 12.879,20 ha (sendo que 30\% está dentro do Município de Lambari e o restante nos municípios de Campanha (59\%) e Cambuquira (11\%) (IEF, Encarte 1, 2010, p.5); já o segundo encarte estabelece área de 15.288,33 ha. [IEF, Encarte 1, 2010, p.5]

Os encartes ainda não são coerentes entre si no que diz respeito aos limites da ZA nos arredores do Bairro de Nova Baden, pois a linha de fronteira demarcada nos mapas da ZA não são idênticos.

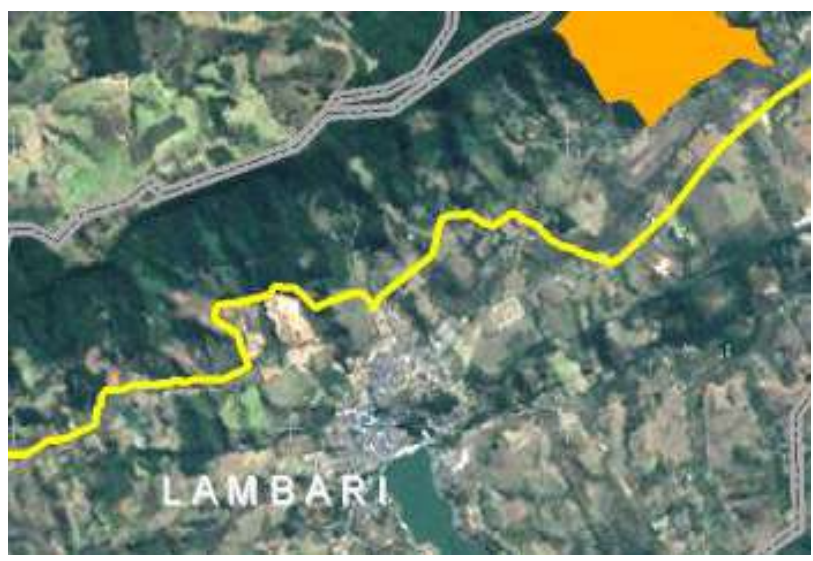

Figura 2: Detalhe do Mapa do encarte 1.

Fonte: IEF, Encarte 1, 2010, p. 6.

Tais discrepâncias podem em tese causar incertezas quanto a limitação e apontam para necessidade de que, na revisão do PM, sejam feitas uma unificação e uma melhor descrição dos limites da ZA do PENB. 


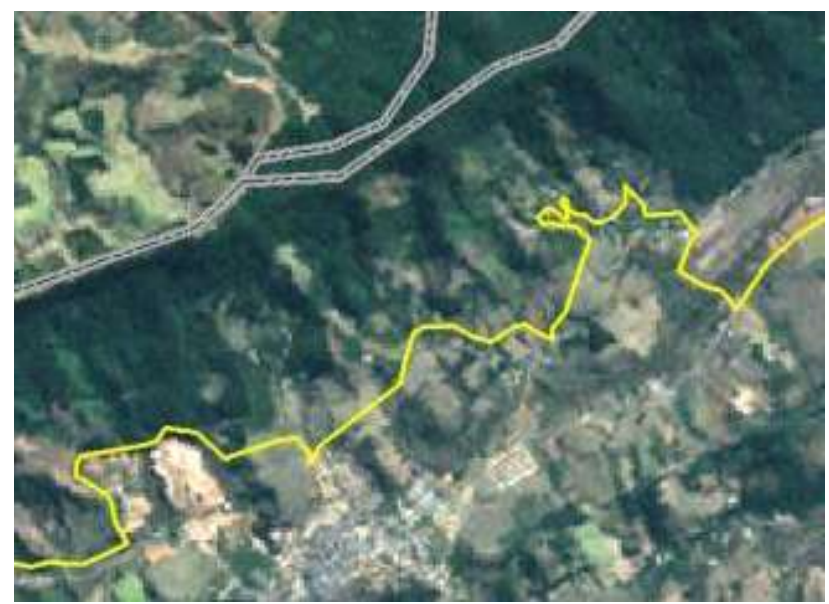

Figura 3: Detalhe do Mapa do encarte 2.

Fonte: IEF, Encarte 2, 2010, p. 14.

\subsubsection{Método de delimitação}

O método de estabelecimento das áreas inclusas na ZA do PENB é ainda criticável.

Conforme acima visto, o PM do PENB estabeleceu como método de limitação da ZA do PENB o Roteiro Metodológico de Planejamento: Parques Nacionais, Reservas Biológicas, Estação Ecológica (RMP). [IBAMA, 2002]

Tal escolha é altamente recomendável, pois o referido documento é instrumento de fácil interpretação e aplicação e, como não existe documento semelhante na legislação mineira e dada a grande semelhança entre parques nacionais e estaduais no que se refere ao objetivos e diretrizes, se presta perfeitamente como integralizador das normas do IEF.
Esse documento dita como ponto de partida para o estabelecimento de ZAs o marco de 10 quilômetros da UC; isso com base na resolução 13/90 do Concelho Nacional do Meio Ambiente - CONAMA.

Ocorre que o método aplicado para o estabelecimento da ZA do PENB não segue perfeitamente o estabelecido pelo RMP. O método proposto pelo RMP é o seguinte:

O limite de $10 \mathrm{~km}$ (Resolução CONAMA 13/90) ao redor da unidade de conservação deverá ser o ponto de partida para a definição da zona de amortecimento. A partir deste limite vai-se aplicando critérios para a inclusão, exclusão e ajuste de áreas da zona de amortecimento, aproximando-a ou afastando-a da UC. A utilização de marcos no campo (linhas férreas, estradas, acidentes geográficos significativos) e o georreferenciamento dos limites facilitam a sua identificação no local. Outro critério a ser analisado como ponto de partida para a definição da zona de amortecimento é o chamado Estudo de Impacto de Vizinhança (EIV), conforme previsto em Lei. [IBAMA, 2002, p. 95 - 96.]

Percebe-se que o perímetro inicial de 10 $\mathrm{km}$ serve como ponto de partida sobre o qual incidem dois critérios modeladores que agem como vetores aumentando ou diminuindo o perímetro com a inclusão ou exclusão de áreas.

No que pese o PM do PENB citar que os critérios de inclusão de áreas foram seguidos, pôde-se perceber que na prática isso não foi 
feito, pois sentido sudoeste da Serra das Águas (na qual se localiza o PENB) a vegetação permanece ininterrupta e altamente preservada muito além dos limites da ZA e assim continua (com poucos intervalos de pastagens, muito menores dos que foram admitidos em outras áreas da ZA) até o fim da Serra das Águas no encontro do a Rodovia Fernão Dias. Desse modo não há interrupção biológica que justifique a limitação arbitrária da ZA em 10 quilômetros da UC no sentido sudoeste da referida serra.

A exclusão de tal área verde é extremamente danosa ao PENB, uma vez que tal UC, devido seu reduzido tamanho e sua disposição geográfica está altamente ligado à Serra das Águas que é em si um corredor ecológico, composto por áreas de APP e grande repositório aquífero da região.

Além disso não foram feitos estudos de impacto de vizinhança ou outros estudos nas áreas circunvizinhas para determinar o potencial ecológico da mesma, muito embora esses sejam recomendados pelo RMP.

Outra informação relevante se refere à descoberta de restos humanos pré-colombianos na localidade conhecida como Toca da Onça na Serra das Águas, pelos professores e alunos da Faculdade de São Lourenço - MG. Muito embora tal área esteja dentro dos limites da ZA do PENB, não há qualquer estudo que demonstre que se trata de sítio único ou se há outros espalhados pela Serra das Águas ou arredores.

Tais situações comprometem a efetividade da ZA e vão contra os ditames dos princípios da precaução e prevenção, além de não atenderem a algumas das diretrizes de inclusão de áreas propostos pelo RMP.

Desse modo urge que se reveja imediatamente os limites da ZA do PENB.

\subsection{Zona de amortecimento como limitação administrativa}

A ZA é espécie peculiar de limitação administrativa, pois constitui-se em limitações incidentes sobre as faculdades de uso, ocupação e modificação da propriedade, para atendimento do interesse público [MEDAUAR, 2014].

Essas restrições têm caráter obrigatório e genérico, impondo-se a todos que estiverem dentro dos parâmetros estabelecidos pelo Poder Público [MEDAUAR, 2014.], no caso a ZA.

Importante aqui ressaltar que no que pesem as obrigações inerentes da incursão de propriedades na ZA, $88 \%$ dos entrevistados disseram não saber o que é uma zona de amortecimento e $94 \%$ afirmaram não saber que sua propriedade está dentro da área de amortecimento do Parque.

Urge ainda ressaltar que todos os entrevistados que disseram saber o que é uma 
ZA e ou que sua propriedade está dentro da ZA do PENB, tiveram ou têm relações de parceria institucional ou trabalho com essa UC.

Para melhor estudo dessas restrições, pode-se dividi-las em quatro grandes grupos, a saber: [1] restrições impostas pelo PM, [2] restrições impostas pela própria lei e não passiveis de serem afastadas pelo PM, [3] restrições impostas pela própria lei e passiveis de serem afastadas pelo PM e [4] obrigações positivas impostas pelo PM ou pela Lei. As quais passa-se a estudar mais profundamente.

\subsubsection{Restrições impostas pelo plano de manejo}

Tratam-se de restrições que se ligam diretamente ao caso particular de cada unidade de conservação, atendendo suas necessidades e não previstas pela legislação de modo prévio. São exemplos as restrições de criação de certos animais ou uso de certos defensivos. [THOMÉ, 2015]

Muito embora esse tipo de restrição, juntamente com as obrigações positivas, ser o núcleo da própria ZA, pois ela permite a individualização da área e a mitigação das ações antrópicas na UC, o PM do PENB é extremamente pobre ao tratar desse fator.

De fato, não existe qualquer atividade proibida ou mitigada por meio do PM.
O único resquício desse tipo de restrição ocorre quando o PM estabelece que:

- Caso se instale na Zona de Amortecimento alguma atividade potencialmente poluidora e de degradação ambiental, durante a vigência do Plano de Manejo, serão adotadas as medidas cabíveis para mitigação dos possíveis impactos sobre a unidade, devendo estas estarem sujeitas à aprovação do IEF; de acordo com a Resolução CONAMA $n^{\circ} 13$, de 06 de dezembro de 1990 e as Deliberações Normativas COPAM n $\mathrm{n}^{\mathrm{0}} 74,123$ e 138 de 09/09/04, 14/08/08 e 12/08/09, respectivamente.

- Considerar os Planos Diretores dos municípios do entorno do PENB (Lambari, Campanha e Cambuquira), para que haja consonância entre suas ações e os objetivos da unidade.[ IEF, Encarte 2, 2010, p. 13]

Ainda quanto ao assunto, chama a intensão o desproporcional grau de subjetividade introduzido nos mandamentos supracitados.

Nesse sentido, seria a princípio possível confundir tal subjetividade com o que Simioni [2011] chama de função; instituto esse que embora tenham um grau de subjetividade, restringe a interpretação e aplicação de determinada norma. Tais funções visam permitir a adaptação da norma ao caso fático, ao mesmo tempo que tem valor diretivo claro, reduzindo subjetividades. É o caso do artigo $1^{\circ}$, $\S 2^{\circ}$, inciso III do antigo Código Florestal Brasileiro. 
Percebe-se que, no caso em contendo, isso não ocorre. O PM não fornece qualquer função que sirva como base para as "medidas cabíveis para mitigação dos possíveis impactos sobre a unidade" [IEF, Encarte 2, 2010, p. 13] ou para a consideração pelo legislador local nos planos diretores de seus municípios.

Poder-se-ia considerar que a referência às normas do COPAM funcionassem como tal função, entretanto esse entendimento, embora auxilie para redução da subjetividade, esvazia mais ainda o conteúdo normativo do PM, pois o PM nada mais estaria fazendo que repetir normas preestabelecidas; ou seja, estaria fazendo letra morta.

Percebe-se que o PM perde a chance de atuar realmente como instrumento de prevenção de impactos no PENB.

Nesse sentido, sugerir-se-ia que na revisão do PM fossem inseridas restrições na ZA que visassem minimizar as pressões e ameaças identificadas no próprio PM, tais como regras de ordenamento do turismo, de restrição/manejo de extrativismo, métodos especiais e restrições ao uso de defensivos agrícolas, restrições a monoculturas e assim por diante.

\subsubsection{Restrições impostas pela própria legislação mas afastáveis pelo plano de manejo}

São restrições que já são previstas pela Lei antes mesmo da criação da UC, mas que podem, conforme as peculiaridades do caso concreto, serem afastadas pelo PM.

É o caso da proibição de cultivo e pesquisa de organismos geneticamente modificados na ZA, que poderá ser liberado mediante condicionantes pelo PM. [THOMÉ, 2015]

Importante aqui ressaltar que o PM do PENB se silenciou nesse sentido, pelo que a restrição ainda vigora na área estudada.

Ocorre que $18 \%$ dos entrevistados disseram produzir ou já ter produzido com sementes transgênicas, destacando-se o plantio de milho transgênico para uso na alimentação de aves. Vale também atentar para o fato de que o próprio Estado descumpria a lei, uma vez que a Empresa de Pesquisa Agropecuária de Minas Gerais - EPAMIG faz o plantio desse tipo de organismo bem diante ao PENB. A esse percentual, pode-se somar mais $27 \%$ dos entrevistados que não sabem o que são produtos transgênicos. Percebe-se assim que a desinformação quanto ao que é organismo transgênico é alarmante. Além disso $9 \%$ dos entrevistados disseram saber o que é produtos 
transgênicos, mas não sabem se os plantam em sua propriedade.

Assim, menos da metade dos proprietários de terras na ZA do PENB, 46\% para ser exato, conhecem o que são produtos transgênicos e não os plantam.

Graficamente tem-se:

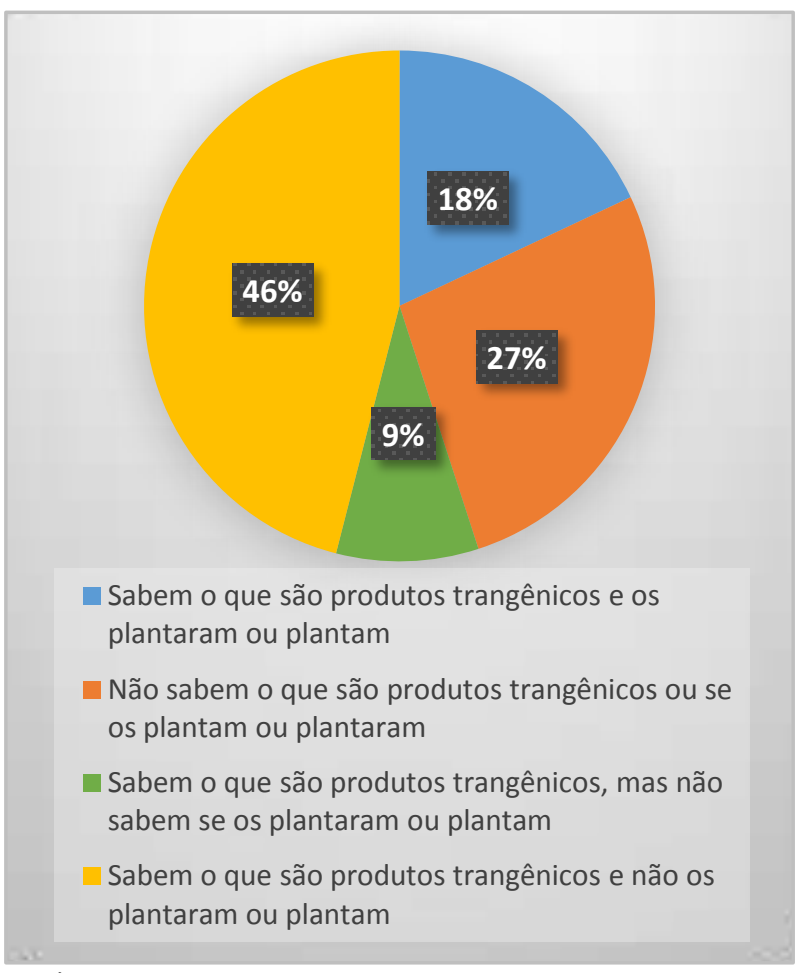

Gráfico 2: Plantio de Transgênicos

Vale aqui ressaltar que o cumprimento da lei não se dá por seu conhecimento, pois todos os entrevistados disseram desconhecer a lei, mas sim pelos proprietários não crerem ser vantajoso o plantio de produtos desse tipo ou por terem receio quanto a segurança de tais organismos.
Portanto, resta preponderante que [1] ou o Estado deixe de descumprir suas próprias leis e trabalhe para conscientizar os produtores rurais da proibição desse cultivo [2] ou seja modificado o PM do PENB de modo a permitir tal plantio; sendo certo que a escolha de qual medida se tomar deve ser embasada em estudos científicos.

\subsubsection{Restrições impostas pela própria lei e não passiveis de serem afastadas pelo plano de manejo}

Essas são disposições legais que restringem o direito de propriedade nas quais a Lei não permite ao PM dispor de modo diverso mais brando.

Exemplo dessa restrição ocorre no caso de as zonas de amortecimento deverem obrigatoriamente serem zonas rurais, não sendo possível o parcelamento do solo por loteamento urbano. [THOMÉ, 2015]

Outra restrição ocorre no caso do uso do fogo, pois segundo o Código Florestal, seu uso somente é possível sob estritos parâmetros.

Quanto ao assunto, deve-se destacar que o próprio plano de manejo identificou ser um risco para UC, mas o PM se silenciou em tomar qualquer medida que dificultasse o uso do fogo em sua ZA. 
Reforçando o descrito no PM, nenhum proprietário declarou fazer uso do fogo em suas atividades.Já quanto à ocorrência de incêndios florestais, $76 \%$ disseram nunca terem sofrido incêndio em sua propriedade, $6 \%$ disseram que sofreram com incêndio há mais de cinco anos e 18\%, há menos de cinco anos. Assim tem-se:

Gráfico 3: Incidência de Incêndios

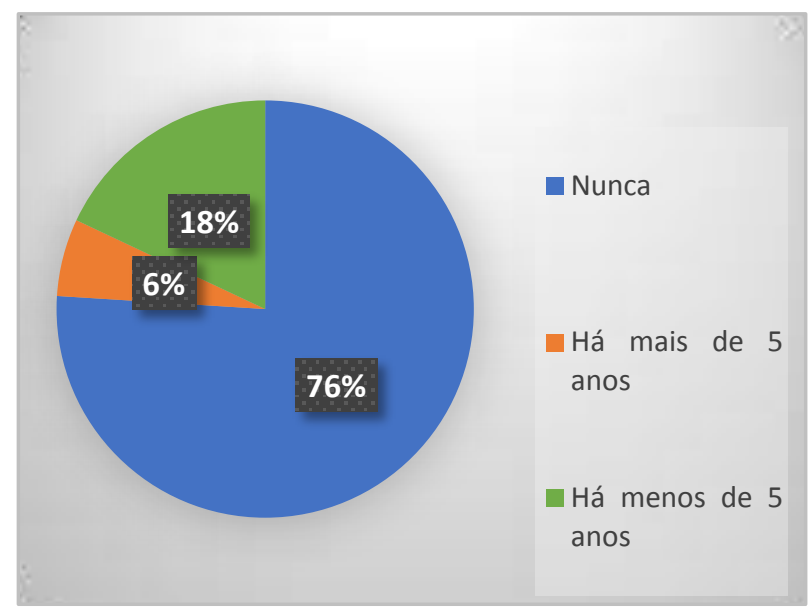

Essa baixa incidência de incêndios, não pode ser correlacionado a medidas preventivas como aceiro, pois em $88 \%$ das propriedades não há aceiro e no restante (12\%) o aceiro é parcial.

Fator correlato ao assunto foi detectado pela pesquisa quando se questionou do uso do solo pois o estudo mostrou que $8 \%$ das propriedades não possuem atividade econômicas em seus imóveis, $8 \%$ se dedicam, como atividade preponderante, à criação de gado, $8 \%$ à exploração do turismo rural e produção de eucalipto concomitantemente, $16 \%$ se dedicam ao cultivo de plantas de lavoura temporária, produção de mudas ou outra forma de produção vegetal de curto ciclo e os outros $60 \%$ se dedicam a produção de café. Graficamente essa proporção pode ser assim representada:

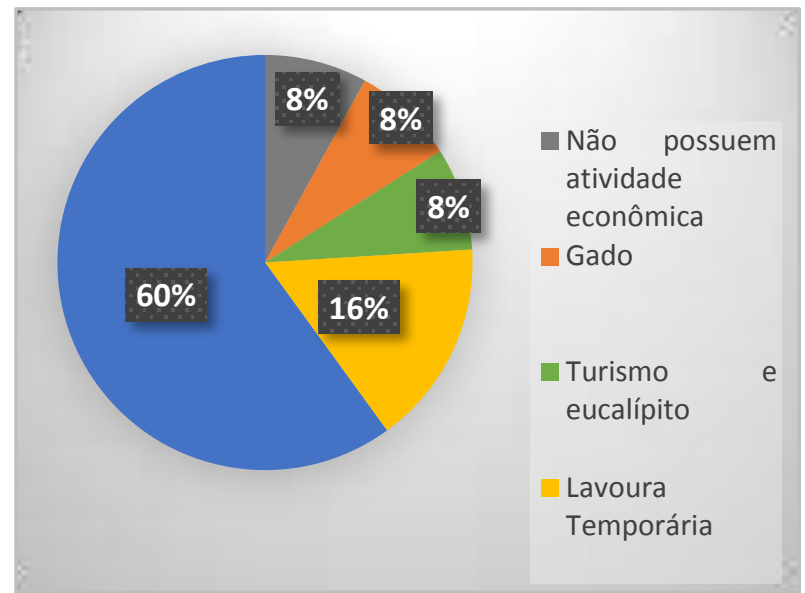

Gráfico 4: Aproveitamento econômico

No caso do cultivo do café, o percentual de $43 \%$ somente se valem desse cultivar, $29 \%$ também produzem economicamente eucalipto em sua propriedade, $14 \%$ também produzem banana e outros $14 \%$ exploram também o turismo rural. Assim a distribuição se dá da seguinte forma: 


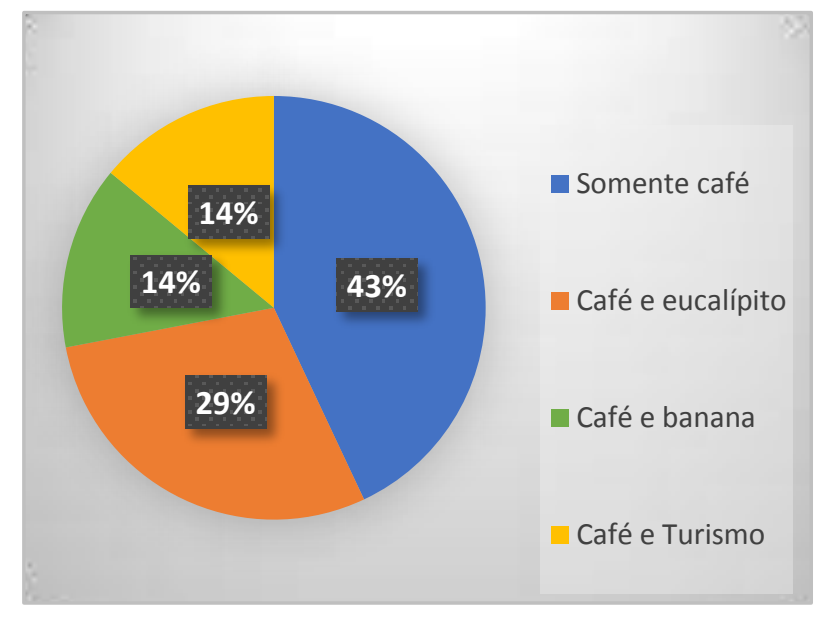

Gráfico 5: Cultivo de Café

Percebeu-se que conforme se afasta do PENB á um aumento significativo do cultivo de café e a redução das demais atividades econômicas, de modo que nos extremos da ZA a única atividade econômica é o plantio do café.

Inversamente, a ocorrência de fogo se concentra nos arredores da UC, o que vai diretamente contra a meta do PM de nulificar tais ocorrências nos arredores da UC, e diminui sensivelmente quando dela se distancia; ao ponto de os proprietários das regiões mais afastadas da UC não se recordarem de incêndios em suas propriedades.

Assim pode-se correlacionar a não incidência de fogo com a maior incidência de plantio de café, pois tal cultura, sendo permanente, é negativamente afetada pela queima.

Isso, descartando-se a conversão de novas áreas ao uso alternativo do solo, e se adotados métodos adequados de uso de defensivos e conservação do solo, bem como o respeito a áreas de preservação permanente e ao percentual de reserva legal, vem a inverter a hipótese de que o cultivo de café é danoso a UC, pois, na verdade, apresenta-se com fator protetor contra incêndios florestais.

\subsubsection{Obrigações impostas pelo plano de manejo}

Muito embora se destaquem as obrigações de não fazer quando se fala em restrições administrativas, urge lembrar que a palavra restrição não está ligado umbilicalmente ao conceito de impedimento, mas sim faz referência à restrição do direito de vontade do particular de se auto determinar.

Portanto é importantíssimo ressaltar que as restrições administrativas, principalmente ambientais, estabelecem parâmetros de comportamento e esses parâmetros podem ser positivos, através de obrigações de fazer, ou negativas, por meio de obrigações de deixar fazer. [DI PIETRO, 2016] 


\subsubsection{Relacionamento do}

Parque com a sociedade civil

O PM impõe a meta de:

Estabelecer $\begin{array}{r}\text { cooperação } \\ \text { Organizações }\end{array}$
$\begin{aligned} & \text { Governamentais } \\ & \text { Governamentais que atuam nâ na }\end{aligned}$
região, para o acompanhamento das
reções a serem realizadas por estas
instituições dentro da ZA.[IEF,
Encarte 2, 2010, p. 13. Grifo nosso]

Ocorre que tal tarefa, no que se refere às organizações não governamentais, se torna dificultosa, já que a pesquisa demostrou que as comunidades da ZA em Lambari se apresentam extremamente desorganizadas do ponto de vista civil, pois nenhum dos entrevistados apontou a existência de sindicatos, associações ou grupos (de mulheres, de jovens, de trabalho ou religiosos), mas tão somente de cooperativas, e mesmo essas somente foram identificadas por 9\% dos entrevistados.

Essa desorganização civil é compatível com o quadro geral do Brasil, no qual os cidadãos dificilmente se organizam civilmente, mas pelo contrário, se isolam da vida comunitária, seja devido a vida precária, baixa escolaridade, informação precária quanto a direitos e deveres [MAGALHÃES, 2008] ou por um sentimento egoístico gerado pela sociedade de consumo [SANTIN, 2003].
Isso gera um contínuo isolamento dos entrevistados, que cada vez mais mantêm fortes vínculos com o centro urbano em detrimento da interação local. Esse fato é facilitado pelo rápido acesso às vias públicas $\mathrm{MG} 456$ e MG 460. Isso pode ser comprovado pelo fato de metade dos entrevistados possuírem um imóvel na sede do município.

O único foco de interação da sociedade civil organizada que pode ser constatado é a existência de cooperativas de café.

O cooperativismo é meio de produção extremamente bem quisto pelo Direito Agrário [OPITZ e OPITZ, 2013] gozando inclusive de status de princípio[MARQUES, 2007]. De fato, cooperativismo e produção rural estão intimamente ligados [CANÇADO e GONTIJO, 2004].

Ocorre que, mesmo esse tipo de organização é fraca, pois conta com pequena parcela da população estudada.

Percebe-se que o pensamento individualista dificulta o cooperativismo [SCOPINHO, 2007], acarretando, no caso estudado que a produção (principalmente de café) seja entregue a atravessadores na zona urbana. Isso fragiliza os produtores, pois, devido à pequena produção individual, têm dificuldade de negociar seu produto em páreo de igualdade. 
Urge assim que o Poder Público, principalmente por meio da gerência do PENB, fomente iniciativas de cooperativismo e associativismo na região, como meio de se melhorar as condições de vida e permanência do homem do campo, além de efetivar os mandamentos do artigo 73 do Estatuto da Terra, que prega o associativismo e o cooperativismo como meio de fomento da atividade rural.

A desorganização civil do entorno do Parque dificulta ainda sua correta administração, pois conforme se lê no decreto $\mathrm{n}^{\mathrm{o}} 4.340 / 02$ que regulamenta o SNUC, o concelho da Unidade deve ser obrigatoriamente composto, dentre outros integrantes, por representante da sociedade civil; mas como fazer isso se não há tais instituições.

Portanto, a situação, muito embora não seja a determinante, pode ser apontada como um dos fatores da ausência do de interação Parque $x$ comunidade, pois inexistem instituições civis organizadas a ponto de interagirem fazendo a ponte entre os entrevistados e o Estado.

Assim o Governo e a própria sociedade devem incentivar a maior interação na comunidade por meio de associações de bairro atuantes, cooperativas de produção ou trabalho e demais formas de organização da sociedade civil.
Por outro lado, a pesquisa demonstrou que a interação com entidades governamentais tem ocorrido, destacando-se a interação com a Fazenda Experimental da EPAMIG, cuja administração declarou ter conhecimento das normas do PM e interagir com sua administração.

\subsubsection{Educação ambiental e capacitação da população}

O PM do PENB estabelece que a obrigação do Estado atuar junto à comunidade da ZA por meio de palestras e cursos que esclareçam a população e a capacite. [IEF, Encarte 2, 2010] Ocorre que a maioria dos entrevistados (89\%) disseram nunca ter participado de palestras, cursos ou campanhas promovidas pelo PENB, 6\% disseram já ter participado dessas ações há menos de 5 anos e $5 \%$ há mais de cinco anos.

Dados esses que demonstram a necessidade de que o Estado, por meio do PENB, organize cursos, palestras e similares de modo a fomentar a educação ambiental.

\subsubsection{Monitoramento de espécies}

Como medida de monitoramento, o PM do PENB determina que: "[sejam] estimulados e feitos, pelo IEF ou sua supervisão, estudos e 
monitoramento de espécies ameaçadas de extinção e endêmicas da flora e da fauna do PENB" [IEF, Encarte 2, 2010, p. 22].

Nesse sentido o PM [IEF, Encarte 2, 2010] determina especial atenção às seguintes espécies: bugio (Alouatta guariba) [SILVA,1994， p.82]， sagui-da-serra-escuro (Callithrixaurita) [AURICCHIO, 1995, p. 59.], trinca-ferro (Saltatorsimilis) [ ANDRADE E ANDRADE, 1992, p. 113].

Visando o monitoramento dessas espécies a pesquisa questionou aos proprietários sobre sua presença sendo que 69\% dos entrevistados disseram haver a presença de bugios em sua propriedade, $50 \%$ afirmaram haver sagui-da-serra-escuro e $75 \%$ já vaiam avistado trincas-ferro em suas terras.

A ocorrência de trinca-ferro foi ainda elencada pelo PM [IEF, Encarte 2, 2010] como indicador de qualidade ambiental juntamente com a ocorrência do palmito-juçara (Euterpe edulis Mart.) [Foto retirada de LORENZI, 1992, p. 279] e da canela-sassafrás (Ocotea odorífera (Vell.) Rohwer) [LORENZI, 1992, p. 127].

Verificou-se baixa incidência do palmito-juçara (6\%) fora dos limites do PENB o que contrapõe a sua alta incidência dentro do PENB.

Tal fato pode indicar que sua extração predatória, conforme descrito por Conte [2004] deve ter reduzido sua distribuição ZA; situação essa confirmada pela vontade dos proprietários vizinhos ao PENB de nele adentrarem com o intuito extrativista dessa espécie.

Por outro lado, a existência de canela sassafrás, no que pese sua relação entre as espécies ameaçadas de extinção segundo a IN 06/2008, é um indicador que a espécie se mantem preservada na área.

Ainda dentro da flora, chama atenção, tanto no PM quanto em loco, a presença da araucária (também conhecida por pinheirobrasileiro ou pinheiro-do-paraná) (Araucariaangustifolia

(Bertol.) Kuntze)[LORENZI, 1992, p. 35], árvore ameaçada de extinção e imune de corte segundo decreto estadual 46.602/2014. Sua presença fora da UC é extremamente reduzida, sendo que somente $37 \%$ dos entrevistados disseram possuir indivíduos dessa espécie em suas terras e em todos os casos disseram os terem plantado. Tal fato pode ser relacionado ou ao esgotamento da área por destruição dos habitats nos quais a espécie proliferava, à coleta predatória ou ainda indicar que a espécie fora introduzida artificialmente no PENB. Tal questão deve ser objeto de estudos de forma urgente.

Além dessas espécies, o PM do PENB cita espécies que são merecedoras de atenção especial, "pois seu desaparecimento pode pôr 
fim a processos ecológicos essenciais, inclusive à sobrevivência de outras espécies" [IEF, Encarte 1, 2010, p. 6 - 7]; são elas a jaguatirica (Felispardalis) [REIS, 2014, p. 92], lontra (Lontra longicaudis) [SILVA,1994, p. 109], tatu-canastra (localmente conhecido como tatupeludo) (Priodontesmaximus) [SILVA, 1994, p. 43], o lobo-guará (Chrysocyonbrachyurus) [SILVA,1994, p. 89] e a onça parda ou suçuarana (Puma concolor) [SILVA,1994, p. 115]. A presença dessas espécies foi relatada conforme a tabela que se segue:

Tabela 1 - Presença de espécies da fauna no PENB.

\begin{tabular}{|l|l|}
\hline Jaguatirica (Felispardalis) & $69 \%$ \\
\hline Lontra (Lontra longicaudis) & $81 \%$ \\
\hline $\begin{array}{l}\text { Tatu-canastra } \\
\text { (Priodontesmaximus) }\end{array}$ & $81 \%$ \\
\hline $\begin{array}{l}\text { Lobo-guará } \\
\text { (Chrysocyonbrachyurus) }\end{array}$ & $69 \%$ \\
\hline \begin{tabular}{l} 
Suçuarana (Puma concolor) \\
\hline
\end{tabular}
\end{tabular}

Deve-se ainda registrar, no que se refere aos grandes mamíferos, que a presença da suçuarana é fato altamente controverso, sendo os relatos pouco confiáveis e sensivelmente menores quantitativamente.

No que se refere às aves, duas espécies se destacaram, por razões diametralmente opostas.

Todos os entrevistados disseram nunca terem visto em suas terras o pica-pau-rei
(Campephilusrobustus) [SICK, 1997, p. 689]; o que pode significar que tal espécie se encontra 'ilhada' no PENB; por outro lado todos reconheceram canário-da-terra (Sicalisflaveola)[ANDRADE, 1992, p. 163], inclusive relatando seu recente ressurgimento, $\mathrm{o}$ que confirma a verificação por Lins [1997] nesse sentido.

Verifica-se assim que apesar de a mata da ZA ter sofrido, em alguns pontos grande agressão, ainda se encontra em bom estado de conservação, ensejando cuidados para sua conservação e eventual fomento.

\subsubsection{Monitoramento de Recursos Hídricos}

Além do monitoramento de espécies o PM estabelece ainda o monitoramento de nascentes, córregos e demais recursos hídricos. [IEF, encarte 2, 2010]

Nesse sentido foram inseridas questões para que se levantasse o atual estado hídrico da ZA, uma vez que não se pôde encontrar qualquer estudo nesse sentido anterior ou posterior ao PM.

No que se refere às nascentes, $23 \%$ das propriedades não as possuem, $41 \%$ possuem somente uma, $18 \%$ possuem duas, em outros $18 \%$ existem três. 


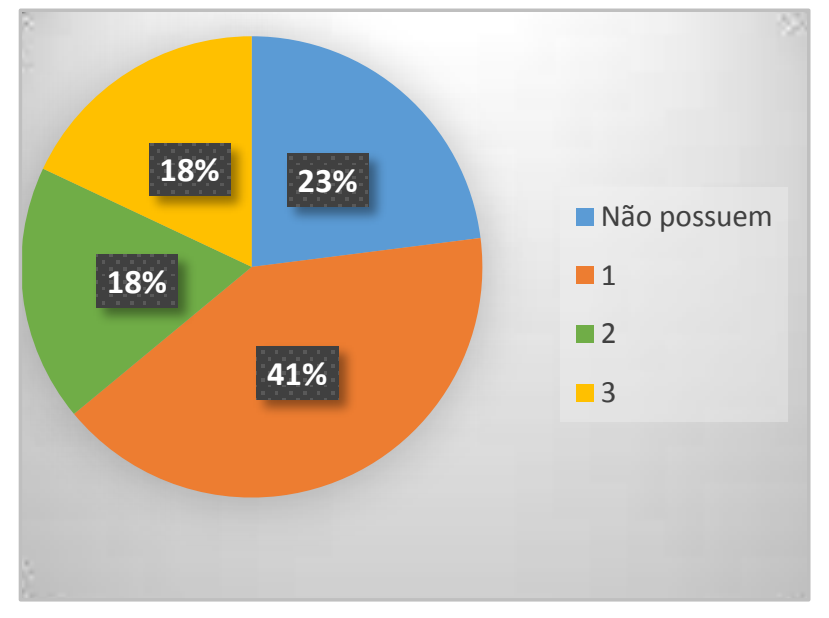

Gráfico 7: Número de nascentes

O número de córregos varia de zero em $13 \%$ dos casos a dois em $20 \%$ das propriedades passando por um córrego em $67 \%$ das propriedades.

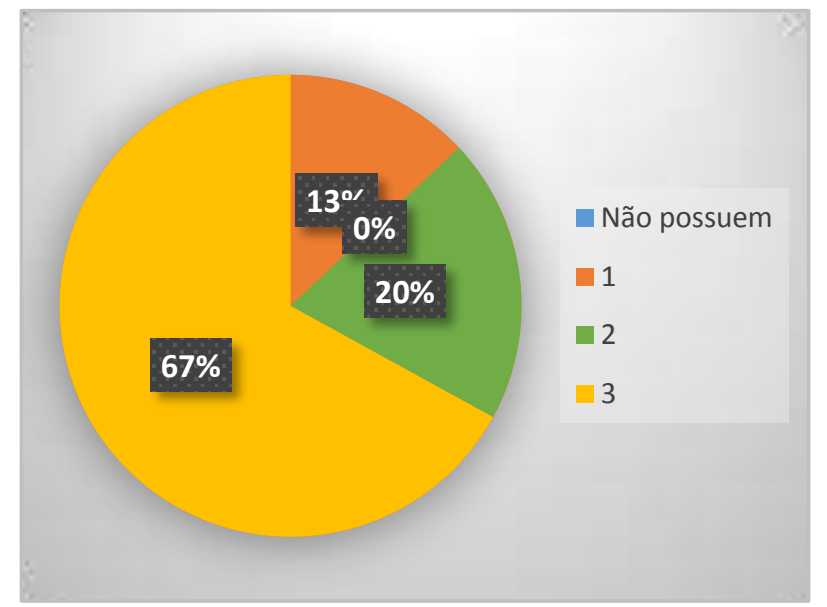

Gráfico 8: Número de Córregos

A captação de água para consumo se distribui por 4 fontes, a saber: nascente na própria propriedade (35\%), córrego na propriedade $18 \%$, poço na própria propriedade $(6 \%)$ e captação em terras vizinhas (41\%). Graficamente tem-se:

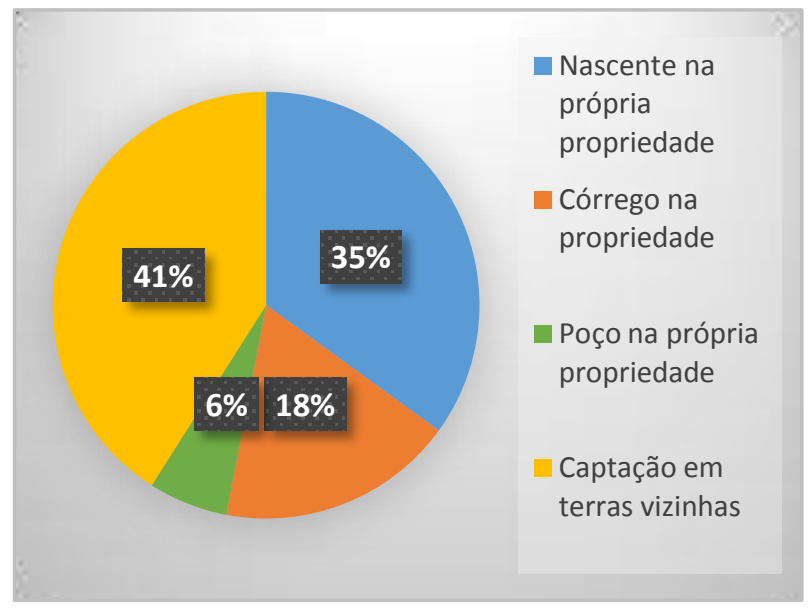

Gráfico 9: Captação de água

Metade das propriedades utiliza fossa seca para destinar seus dejetos humanos, $19 \%$ usam fossa séptica, $31 \%$ despejam o esgoto diretamente em córregos e uma propriedade, a da Fazenda Experimental da EPAMIG, utiliza biodigestor. Graficamente tem-se:

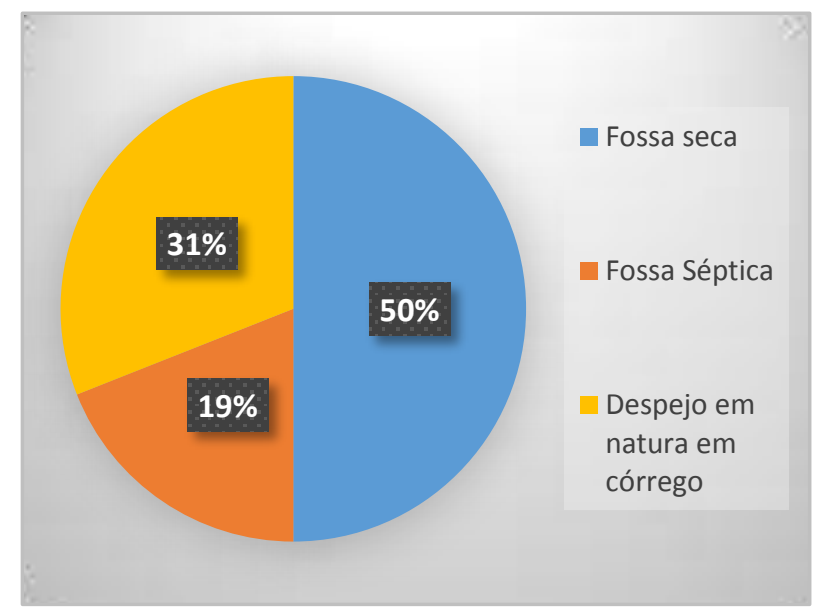

Gráfico 10: Destinação de esgoto 
Vale ressaltar que todos os entrevistados que lançam seus afluentes diretamente em corpos de água se localizam na zona nordeste da pesquisa, destruindo a pureza das aguas que correm diretamente do PENB.

Assim percebeu-se grande abundância de recursos hídricos, mas também igual necessidade de se urgentemente realizar ações de educação e fomento ambientais a fim de se evitar seu esgotamento ou destruição;

\section{Conclusões}

Há necessidade de ser rever no PM a área e os limites da ZA do PENB, deixando-os mais claros nos documentos. Sugere-se ainda que os limites sudoeste da ZA sejam revistos para que se incluam áreas de relevante importância ecológica e se atenda aos ditames normativos.

As disposições do PM quando da introdução de restrições ao poder de propriedade é pobre em disposições restritivas e por outro lado prolífero em obrigações de fazer. Entretanto ambas, sejam estabelecidas por lei ou pelo PM, vem sendo sistematicamente desrespeitadas, inclusive pelo próprio Estado.

O correto uso do solo e uma melhor organização da sociedade civil pode auxiliar a conservação e administração do PENB e de sua ZA.
O PENB tem se apresentado como uma ilha dentro de sua ZA, pois a interação com a comunidade circunvizinha é diminuta, gerando, além do desrespeito à lei e ao PM, um profundo desinteresse da comunidade por ações ligadas ao PENB e pouca visitação na UC; situação essa prejudicial a todos os envolvidos.

Embora haja grande diversidade biológica e hídrica, ambas se encontram ameaçadas pela omissão estatal.

Assim urge que o Estado reveja sua postura perante os proprietários da ZA do PENB, principalmente no que se refere ao cumprimento dos ditames do PM.

\section{Referências Bibliográficas}

ANDRADE, Marco Antônio de. Aves silvestres: Minas Gerais. Belo Horizonte: Concelho Internacional para a Preservação de Aves, 1992.

ANDRADE, Márcia Viegas Greco. PortraitsofBrasilianbirds. Belo Horizonte: Littera Maciel, 1992.

ANTUNES, P. Direito ambiental. São Paulo: Atlas. 2014.

AURICCHIO, Paulo. Primatas do Brasil. São Paulo: Terras Brasilis. 1995.

BORÉM, Rosângela A. Tristão. RAMOS, Doracy Pessoa. Variação estacional e topográfica de nutrientes na serapilheira de um fragmento de mata atlântica. CERNE, v. 8, n.2, p.042-059, 2002 
BRASIL. Constituição da República

Federativa do Brasil. Brasília: Diário Oficial. 1988. Disponível em

http://www.planalto.gov.br/ccivil_03/Constituic ao/Constituicao.htm. Acessado em Acessado em 03 de fevereiro 2016.

BRASIL. Decreto $n^{\circ}$ 4.340. Brasília: Diário Oficial. 2002. Disponível em http://www.planalto.gov.br/ccivil_03/decreto/2 002/d4340.htm. Acessado em Acessado em 03 de fevereiro 2016.

BRASIL. Estatuto da Terra - Lei 4.504. Brasília: Diário Oficial. 1964. Disponível em http://www.planalto.gov.br/CCIVIL_03/leis/L4 504.htm. Acessado em Acessado em 03 de fevereiro 2016

BRASIL. Ministério do Meio Ambiente. Instrução Normativa 06. Brasília: Diário Oficial. 2008. Disponível em http://www.mma.gov.br/estruturas/ascom_bolet ins/_arquivos/83_19092008034949.pdf. Acessado em Acessado em 03 de fevereiro 2016.

BRASIL. Sistema Nacional de Unidades de Conservação - Lei 9.985. Brasília: Diário Oficial. 2000. Disponível em http://www.planalto.gov.br/ccivil_03/LEIS/L99 85.htm. Acessado em Acessado em 03 de fevereiro 2016.

CANÇADO, Airton Cardoso; GONTIJO, Mário César Hamdan. Princípios Cooperativistas: origens, evolução e influência na legislação brasileira. In ENCONTRO DE INVESTIGADORES LATINO-AMERICANO DE COOPERATIVISMO, 3, São Leopoldo, 2004. Anais..., São Leopoldo: UNISINOS, 2004. 1 CD-ROM.

CONTE, Rudimar. Estrutura genética de populações de Euterpe edulis Mart. submetidas à ação antrópica utilizando marcadores alozímicos e microssatélites. Tese de doutorado em Agronomia, na área de concentração genética e melhoramento de plantas. Univercidade do Estado de São Paulo: São Paulo, 2004. Disponível em < http://www.teses.usp.br/teses/disponiveis/11/11 137/tde-19072004-153051/en.php>. Acessado em 03 de outubro 2015.

DI PIETRO, Maria Sylvia Zanella. Direito administrativo. $29^{a}$ Ed. São Paulo: Saraiva. 2016

INSTITUTO BRASILEIRO DO MEIO AMBIENTE E DOS RECURSOS NATURAIS RENOVÁVEIS - IBAMA. Roteiro metodológico de planejamento: parques nacionais, reservas biológicas, estação ecológica. Brasília, 2002.

INSTITUTO ESTADUAL DE FLORESTAS DE MINAS GERAIS - IEF. Parques de Minas. São Paulo: Empresa das Artes. 2006.

INSTITUTO ESTADUAL DE FLORESTAS DE MINAS GERAIS - IEF. Plano de Manejo do Parque Estadual Nova Baden. Encarte 1. Viçosa, 2010. Acesso em 22 de maio de 2015, disponível em Instituto Estadual de Florestas: http://www.ief.mg.gov.br/areasprotegidas/gestao/1691-plano-de-manejo.

INSTITUTO ESTADUAL DE FLORESTAS DE MINAS GERAIS - IEF. Plano de Manejo do Parque Estadual Nova Baden. Encarte 2. Viçosa, 2010. Acesso em 22 de maio de 2015, disponível em Instituto Estadual de Florestas: http://www.ief.mg.gov.br/areasprotegidas/gestao/1691-plano-de-manejo.

INSTITUTO ESTADUAL DE FLORESTAS DE MINAS GERAIS - IEF. Plano de Manejo do Parque Estadual Serra do Papagaio. Belo Horizonte, 2009. Acesso em 22 de maio de 2015, disponível em Instituto Estadual de Florestas: http://www.ief.mg.gov.br/images/stories/Plano_ de_Manejo/serra_papagaio/encarte\%20i.pdf. 
INSTITUTO ESTADUAL DE FLORESTAS DE MINAS GERAIS - IEF. Parque Estadual Nova Baden. Acesso em 22 de maio de 2015, disponível em Instituto Estadual de Florestas: http://www.ief.mg.gov.br/component/content/1 94?task=view. 2015.

\section{INSTITUTO ESTADUAL DE FLORESTAS} DE MINAS GERAIS - IEF. Plano de Manejo. Acesso em 22 de maio de 2015, disponível em Instituto Estadual de

Florestas:http://www.ief.mg.gov.br/areasprotegidas/gestao/1691-plano-de-manejo

LINS, L. V.; MACHADO, A. B. M.; COSTA, C. M. R.; HERRMANN, G. Roteiro metodológico para a elaboração de listas de espécies ameaçadas de extinção (contendo a lista oficial da fauna ameaçada de extinção de Minas Gerais). (Publicações Avulsas da Fundação Biodiversitas, 1997).

LORENZI, Harri. Árvores brasileiras: manual de identificação e cultivo de plantas arbóreas nativas do Brasil. Nova Odessa, SP: Plantarum, 1992.

MACHADO, P. Direito ambiental brasileiro. 12 ed. São Paulo: Malheiros. 2004.

MAGALHÃES, Carla Sanches. Planejamento urbano e participação social: a conferência das cidades e a experiência recente de Duque de Caxias (RJ). Dissertação (mestrado em arquitetura e urbanismo) Universidade Federal Fluminense, Niterói, RJ, 2008.

MARQUES, Benedito Ferreira. Direito agrário brasileiro. 11. ed. São Paulo: Atlas, 2007.

MEDAUAR, O. Direito Administrativo Moderno. 18 ed. São Paulo: Revista dos Tribunais. 2014

MILANO, M. S. Porque existem unidades de Conservação? In: Unidades de Conservação: atualidades e tendências. Curitiba: Fundação O
Boticário de Proteção à Natureza, 2002, p. 193 $-208$.

MILARÉ, É. Direito do ambiente: doutrina, jurisprudência, glossário. São Paulo: Revista dos Tribuinais. 2007

NETTO, D. A. Teoria e Prática - Direito Ambiental.1 vol. Leme, São Paulo: Editora Jurídica. 2009

OPITZ, Silvia C. B.; OPITZ, Osvaldo. Curso completo de Direito agrário. 7. ed. São Paulo: Saraiva, 2013.

SANTIN, Janaína Rigo, Estatuto da cidade e a gestão democrática municipal. Interesse público. Porto Alegre, RS. Ano 5, no 21, p.205 a 215, 2003.

SILVA, Flávio. Mamíferos silvestres. Porto Alegre: Fundação Zoobotânica do Rio Grande do Sul, 1994.

SIMIONI, Rafael Lazzaroto. Direito ambiental e sustentabilidade. Curitiba, PR: Juruá, 2011.

SCOPINHO, Rosemeire Aparecida. Sobre cooperação e cooperativas em assentamentos rurais.Psicologia \& Sociedade; 19, Edição Especial 1: 84-94, 2007

THOMÉ, R. Manual de Direito Ambiental. Salvador: Juspodivm. 2015.

VIO, A. P. A. 2001. Zona de amortecimento e corredores ecológicos. In: BENJAMIN, A. H. Direito ambiental das áreas protegidas - $\mathrm{O}$ regime jurídico das Unidades de Conservação. Rio de Janeiro: Forense Universitária, p. 348360. 